\title{
Uterine Fibroid Symptom - Quality of Life questionnaire translation and validation into Brazilian Portuguese
}

\section{Tradução e validação para língua portuguesa do questionário Uterine Fibroid Symptom - Quality of Life}

\author{
Rita Oliveira da Silva ${ }^{1}$ Mariano Tamura Vieira Gomes ${ }^{1}$ Rodrigo de Aquino Castro ${ }^{1}$ \\ Cláudio Emílio Bonduki ${ }^{1}$ Manoel João Batista Castello Girão ${ }^{2}$
}

${ }^{1}$ Division of General Gynecology, Uterine Fibroid Sector, Escola Paulista de Medicina, Universidade Federal de São Paulo (EPM/ Unifesp), São Paulo, SP, Brasil

2 Escola Paulista de Medicina, Universidade Federal de São Paulo (EPM/UNIFESP), São Paulo, SP, Brasil

Rev Bras Ginecol Obstet 2016;38:518-523.

\begin{abstract}
Address for correspondence Rita Oliveira da Silva, MSc, Rua Napoleão de Barros, $715,7^{\circ}$ andar, Vila Clementino, 04024-002, São Paulo, SP, Brazil (e-mail: rita@clinicarezende.com.br).
\end{abstract}

\begin{abstract}
Keywords

- leiomyoma

- questionnaire

- quality of life

- validation studies

- translation

Purpose To translate into Portuguese, culturally adapt and validate the Uterine Fibroid Symptom - Quality of Life (UFS-QoL) questionnaire for Brazilian women with uterine leiomyoma.

Methods Initially, the UFS-QoL questionnaire was translated into Brazilian Portuguese in accordance with international standards, with subsequent cultural, structural, conceptual and semantic adaptations, so that patients were able to properly answer the questionnaire. Fifty patients with uterine leiomyoma and 19 patients without the disease, confirmed by abdominal pelvic examination and/or transvaginal ultrasound, were selected at the outpatient clinics of the Department of Gynecology of the Universidade Federal de São Paulo (Unifesp). The UFS-QoL questionnaire was administered to all women twice on the same day, with two different interviewers, with an interval of 15 minutes between interviews. After 15 days, the questionnaire was readministered by the first interviewer. Reliability (internal consistency and test-retest), construct and discriminative validity were tested to ratify the questionnaire.

Results The reliability of the instrument was assessed by Cronbach's $\alpha$ coefficient with an overall result of 0.97 , indicating high reliability. The survey results showed a high correlation ( $p=0.94 ; p \leq 0.001)$.

Conclusion The UFS-QoL questionnaire was successfully adapted to the Brazilian Portuguese language and Brazilian culture, showing reliability and validity.
\end{abstract}

received

December 3, 2015

accepted

July 27, 2016

published online

November 10, 2016
DOI http://dx.doi.org/

$10.1055 / \mathrm{s}-0036-1593833$.

ISSN 0100-7203.
Copyright $\odot 2016$ by Thieme Publicações License terms

Ltda, Rio de Janeiro, Brazil
(®) $\Theta \circledast$ 


\section{Resumo}

\section{Palavras-chave}

- leiomioma

- questionário

- qualidade de vida

- estudos de validação

- tradução
Objetivo Traduzir para o português, adaptar culturalmente e validar o questionário Uterine Fibroid Symptom - Quality of Life (UFS-QoL) para as mulheres brasileiras com leiomioma uterino.

Métodos Inicialmente, o questionário UFS-QoL foi traduzido para o português brasileiro, em conformidade com as normas internacionais, com adaptações culturais, estruturais, conceituais e semânticas subsequentes, de modo que as pacientes fossem capazes de responder o questionário de forma adequada. Cinquenta pacientes com leiomioma uterino e 19 pacientes sem a doença, confirmada por exame pélvico abdominal e/ou ultrassonografia transvaginal, foram selecionados nos ambulatórios do Departamento de Ginecologia da Universidade Federal de São Paulo (Unifesp). A todas as mulheres foi administrado o questionário UFS-QoL por duas vezes no mesmo dia, por dois entrevistadores diferentes, com um intervalo de 15 minutos entre as entrevistas. Após 15 dias, o questionário foi novamente administrado pelo primeiro entrevistador. Confiabilidade (consistência interna e teste-reteste), constructo e validade discriminativa foram testados para ratificar o questionário.

Resultados A confiabilidade do instrumento foi avaliada pelo coeficiente $\alpha$ de Cronbach com um resultado global de 0,97 , indicando alta confiabilidade. Os resultados da pesquisa mostraram uma correlação elevada $(p=0,94 ; p \leq 0,001)$.

Conclusão $O$ questionário UFS-QoL foi adaptado com sucesso para a língua portuguesa e cultura brasileira, mostrando confiabilidade e validade.

\section{Introduction}

Uterine leiomyomas are the most common benign tumors of the female pelvis, affecting $20-30 \%$ of women at childbearing age, and more than $40 \%$ of women over 40 years old. ${ }^{1-3}$ Although there are few epidemiological studies to investigate this condition in Brazil, its prevalence is of $\sim 23.3 \%$ of the female population. ${ }^{4}$ Smoking, physical exercise, a restricted diet low in fats and rich in vegetables, multiparity and contraceptive use are thought to be protective mechanisms due to their anti-estrogenic effects. ${ }^{2-8}$

These tumors can cause a variety of symptoms, including menstrual disorders, pelvic pain, infertility, sexual dysfunction, urinary incontinence, and pelvic pressure increase, and they can adversely impact pregnancy. ${ }^{4,8-10}$ Many symptoms experienced by the patients are subjective, regardless of the amount, volume and location of the tumors. For a variety of reasons, including medical and psychological ones, hysterectomy is not desirable for many women. ${ }^{4-6}$ Evaluating the impact caused by uterine leiomyoma on women's quality of life is a constant challenge for researchers and clinicians. Quality of life is a subjective and multidimensional construct, based on the individual's perception of the position of their life in the cultural context and value systems in which they live, in relation to their objectives, expectations, standards and concerns. The absence of a suitable tool makes the assessment of the disease difficult.

In 2002, Spies et al ${ }^{11}$ published a specific questionnaire for assessing the severity of the disease symptoms and their impact on quality of life, the Uterine Fibroid Symptom Quality of Life (UFS-QoL). This instrument was a milestone in the medical literature. The purpose of the questionnaire is to provide a simple tool to assess the impact from the perspective of the patient. ${ }^{1,10-13}$

The UFS-QoL questionnaire has been chosen to be validated in Brazilian Portuguese as the only specific clinical questionnaire to assess patients with uterine leiomyoma that included psychometric properties in its development.

\section{Methods}

This study is an observational case-control study evaluating a quality of life questionnaire for patients with uterine leiomyoma, held at the Uterine Fibroid Section of the Department of Gynecology at Universidade Federal de São Paulo. It was submitted and approved by the Research Ethics Committee of the Institution (Protocol 1488/10), and all participants signed a consent form before answering the questionnaire.

A total of 69 women aged between 20 and 50 were included in the study. Of these, 50 women had clinical and ultrasound diagnoses of uterine leiomyoma, with no prior treatment for the disease, no use of any hormonal medication containing estrogen and/or progestin, no pregnancies or menopause and without present malignant pelvic gynecological diseases and/or other benign uterine diseases (case). Nineteen participants had no uterine myoma (control).

The study was conducted in five steps: prior authorization request, translation and cultural adaptation of the questionnaire, pilot test, test-retest and validation.

Initially, an authorization from the author of the UFSQoL questionnaire, ${ }^{11}$ James B. Spies, MD, MPH, for its 
translation and use was requested. After the request was accepted, a Brazilian translator with proficiency in American English and scientific knowledge of the subject translated the questionnaire from American English into Brazilian Portuguese. Next, the validation was performed through linguistic and cultural adjustments. In this first phase of cultural adaptation of the original questionnaire, five health professionals with knowledge in both American English and Brazilian Portuguese were selected from various areas to identify and discuss differences to choose the final version.

The UFS-QoL questionnaire consists of 37 questions, divided in 2 parts. The first part is composed of a single domain. The second is divided in six areas, where the answer options are in the Li Kert format. The first part evaluates the severity of the symptoms, with points assigned to each answer option. This domain allows raw total scores from 8 to 40 . For the calculation of scores, their sum was denoted as the raw score. In sequence, these scores were added and transformed and labeled as the transformed scores (the higher the score, the more severe the symptoms). The second part evaluates the health-related quality of life (HRQL), which is divided into 6 areas: concern, daily activities, changes in mood and energy, self-control, self-consciousness and sexual function.

To calculate the transformed score of the HRQL, the values for each field ( 1 to 5 ) were added, yielding the raw scores and becoming values in the specified formula. This domain allows gross total scores from 29 to 145 . The higher the score, the better the quality of life in relation to health.

Later, the questionnaire was submitted to back-translation to American English by an American native translator with proficiency in the Brazilian Portuguese language (without mutual consultation between the two translators), to make the review of the versions of the questionnaire possible by comparing them to the original. The two translations were used to establish a consensus version, so that there was no discrepancy between the retranslation and the original questionnaire, following the guidelines of the MAPI Institute (Lyon, France).

Sixty-nine patients were interviewed in three phases: E1, E2 and E3. On the same day, interviews E1 and E2 were performed separately by different interviewers (P1 and P2). Fifteen days after, a third interview (E3) was performed by the first interviewer (P1).

The final validation of the UFS-QoL questionnaire was performed by assessing the reliability (internal consistency, intraclass correlation coefficients, intraobserver reproducibility and test-retest) and validity of the construct, as well as the discriminative validity.

For data analysis, the following programs were used: SPSS V17 (SPSS Inc. Apache Software Foundation, Forest Hill, Maryland, US), Minitab 16 (State College, Pa., US) and Office ${ }^{\circledR}$ Excel 2010 (Microsoft ${ }^{\circledR}$, (C) 2012 Microsoft Corporation, Impressa Systems, Santa Rosa, California, US).

A descriptive analysis of the demographic data was performed, and the Analysis of Variance (ANOVA) statistical test was used, which compares means using the variance and the Two Proportion Equality test, to compare the proportion of two given varying responses and/or whether their levels are statistically significant.

Psychometric analyses were conducted to assess the severity scales of symptoms and the internal consistency of the quality of life assessed by the UFS-QoL questionnaire using Cronbach's $\alpha(\alpha)$, intraclass correlation coefficient (or reproducibility test) and Pearson's correlation coefficient. All statistical tests showed a 5\% significance level.

\section{Results}

The sample consisted of 69 women, 50 of them with uterine leiomyoma (case) and 19 subjects without the disease (control). Of the 50 patients with myoma, $62 \%$ were aged between 35 and 45 years. The clinical and demographic characteristics of each group are shown in - Tables 1 and 2. Most patients with uterine leiomyoma were single (44\%), engaged in remunerated activities throughout the day (58\%), self-reported as white (44\%) and had studied through elementary school grade 2 (14\%). The groups were statistically homogeneous in terms of number of pregnancies, births, miscarriages and body mass index (BMI).

The average uterine volume between the patients with leiomyoma was $250 \mathrm{~cm}^{3}$, while those with no uterine myoma had a mean volume of $60 \mathrm{~cm}^{3}$; thus, the groups were statistically heterogeneous. This difference between groups is reflected by the clinical characteristics inherent to uterine leiomyoma, showing that patients with myoma had a longer duration of menstrual bleeding (6.7 days) accompanied by dysmenorrhea (84\%) and shorter intervals between menstrual cycles (23 days).

- Table 3 shows the estimated reliability of the questionnaire. The values of Cronbach's $\alpha$ coefficients are high and satisfactory. The final internal consistency is more than 0.960 , which is defined as excellent.

The UFS-QoL questionnaire domains were also able to discriminate uterine leiomyoma patients from women with no myoma (-Table 4 ).

There was a statistically significant mean difference between groups for almost all areas except for the self-consciousness and sexual function subscales. The uterine leiomyomata group average for HRQL was 90.3 compared with 67.4 for the normal group ( $p=0.004)$.

The time interval between the first and second interviews was 15 minutes. The intraclass interobserver correlation coefficients were between 92.8\% (95\% CI [87.3; 95.9]) and 97.2\% (95\% CI [95.1; 98.4]). These results indicate a strong correlation between the two interviewers at different times and on the same day, while keeping in mind that the two groups are statistically homogeneous.

Intraclass intraobserver correlation coefficients were between $84.7 \%$ (95\% CI $[73.1 ; 91.3])$ and 97.4\% (95\%CI [95.3; 98.5]), reflecting a strong correlation between the 2 interviewers at different times and on the same day.

\section{Discussion}

Evaluating the impact caused by uterine leiomyoma on the quality of life in women is a constant challenge for 
Table 1 Clinical and demographic characteristics

\begin{tabular}{|c|c|c|c|}
\hline & Control $(N=19)$ & $\begin{array}{l}\text { Case } \\
(N=50)\end{array}$ & $p$ \\
\hline \multicolumn{4}{|l|}{ Age (\%) } \\
\hline $\begin{array}{l}\text { Less than } 35 \\
\text { Between } 35 \text { and } 45\end{array}$ & $\begin{array}{l}6(31.6) \\
9(47.4)\end{array}$ & $\begin{array}{l}5(10) \\
31(62)\end{array}$ & $0.12^{1}$ \\
\hline More than 45 & $4(21.1)$ & $14(28)$ & \\
\hline \multicolumn{4}{|l|}{ Race (\%) } \\
\hline Asian & 0 & $1(2)$ & \multirow[t]{3}{*}{$0.22^{2}$} \\
\hline White & $14(73.7)$ & $22(44)$ & \\
\hline Indigenous & 0 & $1(2)$ & \\
\hline Black & $3(15.8)$ & $11(22)$ & \\
\hline Brown & $2(10.5)$ & $15(30)$ & \\
\hline \multicolumn{4}{|l|}{ Employment Status (\%) } \\
\hline No, retired & $1(5.3)$ & $4(8)$ & \multirow[t]{2}{*}{$>0.999^{1}$} \\
\hline No, unemployed & $3(15.8)$ & $7(14)$ & \\
\hline Homemaker & $1(5.3)$ & $4(8)$ & \\
\hline Yes, full time & $12(63.2)$ & $29(58)$ & \\
\hline Yes, part-time & $2(10.5)$ & $6(12)$ & \\
\hline \multicolumn{4}{|l|}{ Marital Status (\%) } \\
\hline Married & $10(52.6)$ & $20(40)$ & $0.34^{2}$ \\
\hline Divorced & $2(10.5)$ & $3(6)$ & $0.52^{2}$ \\
\hline Separated & 0 & $4(8)$ & $0.20^{2}$ \\
\hline Single & $7(36.8)$ & $22(44)$ & $0.59^{2}$ \\
\hline Widowed & 0 & $1(2)$ & $0.53^{2}$ \\
\hline \multicolumn{4}{|l|}{ Pregnancies } \\
\hline Mean (SD) & $2.1(2.4)$ & $2.1(1.94)$ & $0.96^{1}$ \\
\hline \multicolumn{4}{|l|}{ Parity } \\
\hline Mean (SD) & $1.5(1.3)$ & $1.6(1.8)$ & $0.87^{1}$ \\
\hline \multicolumn{4}{|l|}{ Miscarriage } \\
\hline Mean (SD) & $0.6(1.3)$ & $0.5(0.9)$ & $0.75^{1}$ \\
\hline \multicolumn{4}{|l|}{ BMI $\left(\mathrm{Kg} / \mathrm{m}^{2}\right)$} \\
\hline Mean (SD) & $27.6(6.2)$ & $25.8(4.3)$ & $0.17^{1}$ \\
\hline \multicolumn{4}{|l|}{ Level of education (\%) } \\
\hline Illiterate & 0 & $2(4)$ & \multirow[t]{10}{*}{$0.09^{2}$} \\
\hline Full elementary school grade 1 & 0 & $2(4)$ & \\
\hline Incomplete elementary school grade 1 & $2(10.5)$ & $4(8)$ & \\
\hline Full elementary school grade 2 & 0 & $7(14)$ & \\
\hline Incomplete elementary school grade 2 & $2(10.5)$ & $12(24)$ & \\
\hline Full high school & $10(52.6)$ & $11(22)$ & \\
\hline Incomplete high school & 0 & $4(8)$ & \\
\hline Complete college education & $2(10.5)$ & $6(12)$ & \\
\hline Incomplete college education & $2(10.5)$ & $2(4)$ & \\
\hline Post-graduate & $1(5.3)$ & 0 & \\
\hline
\end{tabular}

Abbreviation: BMI, body mass index; SD, standard deviation.

${ }^{1}$ ANOVA test.

${ }^{2}$ Two Proportions Equality Test. 
Table 2 Clinical characteristics inherent to uterine leiomyoma

\begin{tabular}{|c|c|c|c|}
\hline & $\begin{array}{l}\text { Control } \\
(N=19)\end{array}$ & $\begin{array}{l}\text { Case } \\
(N=50)\end{array}$ & $p$ \\
\hline \multicolumn{4}{|c|}{ Duration of menstrual bleeding (d) } \\
\hline Mean (SD) & $5.4(2.0)$ & $6.7(4.2)$ & $0.20^{1}$ \\
\hline \multicolumn{4}{|c|}{ Intermenstrual interval (d) } \\
\hline Mean (SD) & $34(16.2)$ & $23.0(8.7)$ & $0.001^{1}$ \\
\hline \multicolumn{4}{|c|}{ Uterine Volume $\left(\mathrm{cm}^{3}\right)$} \\
\hline Mean (SD) & $60(22.1)$ & $250(104.8)$ & $0.0001^{1}$ \\
\hline \multicolumn{4}{|c|}{ Dysmenorrhea $(\mathrm{N})(\%)$} \\
\hline No & $14(73.7)$ & $8(16)$ & \multirow[t]{2}{*}{$<0.001^{2}$} \\
\hline Yes & $5(26.3)$ & $42(84)$ & \\
\hline
\end{tabular}

Abbreviation: SD, standard deviation.

${ }^{1}$ ANOVA test.

${ }^{2}$ Two Proportions Equality Test.

Table 3 Reliability estimate of the UFS-QoL questionnaire*: internal consistency

\begin{tabular}{|l|l|l|}
\hline UFS-QoL Subscales & $\begin{array}{l}\text { Number of items } \\
(\mathbf{k})\end{array}$ & $\begin{array}{l}\text { Cronbach's } \boldsymbol{\alpha} \\
(\boldsymbol{\alpha})\end{array}$ \\
\hline Symptom severity & 8 & 0.920 \\
\hline Concern & 5 & 0.866 \\
\hline Activities & 7 & 0.859 \\
\hline Energy/mood & 7 & 0.933 \\
\hline Control & 5 & 0.852 \\
\hline Self-consciousness & 3 & 0.807 \\
\hline Sexual function & 2 & 0.757 \\
\hline HRQL total & 29 & 0.971 \\
\hline
\end{tabular}

Abbreviations: HRQL, health-related quality of life; UFS-QoL, Uterine Fibroid Symptom - Quality of Life.

Table 4 Discriminant validity of the UFS-QoL questionnaire

\begin{tabular}{|l|l|l|r|}
\hline $\begin{array}{l}\text { UFS-QoL Subscales: } \\
\text { mean (SD) }\end{array}$ & $\begin{array}{l}\text { Control } \\
(N=19)\end{array}$ & $\begin{array}{l}\text { Case } \\
(N=50)\end{array}$ & $p^{1}$ \\
\hline Symptom severity & $25.3(17.5)$ & $60(26.9)$ & $<0.001$ \\
\hline Concern & $61.1(23.8)$ & $40.2(32.5)$ & 0.01 \\
\hline Activities & $72.6(19.5)$ & $57.1(29.0)$ & 0.04 \\
\hline Energy/mood & $63.4(29.3)$ & $42.5(31.2)$ & 0.01 \\
\hline Control & $76.3(17.8)$ & $47.3(28.7)$ & $<0.001$ \\
\hline Self-consciousness & $67.1(27.6)$ & $50.3(36.1)$ & 0.07 \\
\hline Sexual function & $50(31.5)$ & $38.5(24.6)$ & 0.11 \\
\hline HRQL total & $67.4(23.1)$ & $90.3(30.5)$ & 0.004 \\
\hline
\end{tabular}

Abbreviations: HRQL, health-related quality of life; SD, standard deviation; UFS-QoL, Uterine Fibroid Symptom - Quality of Life.

${ }^{1}$ ANOVA t-test; $p \leq 0.05$. researchers and clinicians. Women suffering from the disease exhibit significant symptoms, including menstrual irregularities, pelvic pain, infertility, sexual dysfunction, edema, urinary urge incontinence, pelvic pressure and adverse impacts on pregnancy.

Psychological tests are tools, and in order to benefit from them, one must know how to evaluate them and what types of information can be provided. No psychological test can do more than measure behavior; therefore, customizing the test is an important step to ensure uniformity.

Uterine leiomyoma is a prevalent disease, and in 2002 Spies et $\mathrm{al}^{11}$ published a specific instrument for the assessment of symptom severity for this disease and its impact on the quality of life. The purpose of the questionnaire was to provide a simple tool to assess the impact of this disease from the patient's perspective.

In this study, the questionnaire was translated and administered to Brazilian women who suffer from uterine leiomyoma. It is an easy-to-understand questionnaire, but it is not self-administered in our culture because we do not have this habit in Brazil.

The administration time varied between 15 and $20 \mathrm{mi}-$ nutes. The patients also made use of this time to reflect more about the disease, emphasizing to the interviewer the angst and inconvenience caused by myomas in their lives.

The original questions were formulated in a complex manner, and had to be adapted into colloquial language. This change was required because when faced with cultured written language, patients may have difficulty understanding it. We worked with a literal translation, trying not to change the meaning because words must be accurate, clear and objective.

Everyday examples were used to obtain consistent answers, curbing misinterpretation by the patients. The content of an item may be more familiar in one culture than in another, and the subtlest differences can significantly affect the performance of a test.

Even when reducing the cultural differences in a test, cross-cultural tests do not completely eliminate this difference. The way the test is administered can have diverse impacts in different ethnic/cultural groups. The mere existence of culture stereotypes can affect individual performance in a test. This is called stereotypical vulnerability, and it influences the test scores for both genders in ethnic comparisons.

When language differences in translation occur, problems regarding the compatibility of standards and the equivalence of scores arise. One should also remember that a simple translation is rarely sufficient, and adjustments or reviews are always required. In this study, in a second meeting with the clinical team, there was consensus that after retranslation there was no difference in meaning in the questions in the cultural adaptation, which, in fact, could be verified in the pilot study. Thus, modifying terms and/or words was no longer necessary, and the test was ready to be administered. There was some degree of difficulty in making cultural adaptations to the Brazilian culture. Although most patients in our clinic had 
more than 8 years of formal education, several changes in words and expressions were necessary so that the questionnaire was properly understood.

As racial categorization in Brazil is very particular when compared with other parts of the world, women with similar phenotypes were probably classified as different groups of color/race, showing the fluidity in the Brazilian concept of color/race and some lack of precision on this kind of information when based only on physical characteristics. $^{12}$

The reliability and validity of an instrument evaluating a patient's quality of life are key criteria. Reliable measurements are reproducible, consistent and coherent, and always give the same result because they are stable and valid measurements, and accurate representations of the features to be measured. The behavior to be tested must be systematically analyzed to ensure the test items cover all aspects and that they are in the correct proportions. The UFS-QoL questionnaire has an excellent discriminative capacity, not only to differentiate ill patients from healthy ones. However, the fields related to self-consciousness and sexual function were similar in both groups. The self-conscious factor is related to situations where the woman is prone to potential embarrassment at any time or in each menstrual period, creating a degree of anxiety that may disrupt her daily life or its planning. Besides, the sample size may not have been large enough to show a difference in these areas between the two groups.

However, it is important to emphasize the high reliability of the questionnaire as shown by Cronbach's $\alpha$ for both the total score and the evaluation of each domain. When reporting retest reliability, the time interval between surveys should always be cited, because correlation falls progressively just as interval time between visits increases. The time interval should not exceed more than six months. On the other hand, the interval between interviews should not be too short because the subject can recall many of the answers she gave, and they become invalid. In that case, the scores do not end up being acquired independently so that the correlation between them is not falsely high. The interval between the first and second interviews was 15 minutes. The intraclass interobserver correlation coefficients were between $92.8 \%$ and $98.1 \%$, showing a strong correlation between the responses of the patients to each question within each domain to the two interviewers (at different times and on the same day). The intraclass intraobserver correlation coefficients also show a strong correlation between the patient's responses to each question within each domain to the same interviewer on different days.

As uterine leiomyoma has a critical impact on patients' lives, health care providers should focus on guiding them to recovery. With the specific evaluation of the quality of life related to a specific condition, the professional should be able to measure the impact of the disease. Above all, the quality of life questionnaires offer excellent ways to begin a dialogue between patient and doctor, and the validity reflects the competence of an instrument to accurately mea- sure the phenomenon under study. The impact assessment of uterine leiomyoma on women's quality of life is very important because it serves to test whether our treatments are truly effective, and it evaluates the impact of the disease in the population globally.

The adaptation of the UFS-QoL questionnaire for the Brazilian culture has proven to be reliable and valid, making it able to distinguish the different degrees of severity of symptoms caused by uterine leiomyoma and consequently their impact on women quality of life. This instrument should be used as a tool to assess the quality of life in clinical trials involving uterine leiomyoma because it allows the measurement of the result of a therapeutic intervention in relation to the patient's quality of life. In addition, it can also compare different therapeutic interventions from the perspective of quality of life of Brazilian women.

\section{References}

1 Bozzini N, Ed. Leiomioma uterino: manual de orientação FEBRASGO. São Paulo: Ponto; 2004

2 Rodrigues CJ, Bozzini ABR, Padilla FA. Epidemiologia do mioma uterino. In: Bozzini N. organizador. Leiomioma uterino. São Paulo: PlanMark; 2005. p. 42-47

3 Gomes MT, Castro RA, Silva ID, Baracat EC, Lima GR, Girão MJ. Análise da patogênese do leiomioma do útero. Femina 2006;34(6):381-387

4 Boclin KL, Faerstein E. Prevalência de diagnóstico médico autorelatado de miomas uterinos em população brasileira: padrões demográficos e socioeconômicos no Estudo Pró-Saúde. Rev Bras Epidemiol 2013;16(2):310-313

5 Huyck KL, Panhuysen CIM, Cuenco KT, et al. The impact of race as a risk factor for symptom severity and age at diagnosis of uterine leiomyomata among affected sisters. Am J Obstet Gynecol 2008; 198(2):168.e1-168.e9

6 Spies JB, Bradley LD, Guido R, Maxwell GL, Levine BA, Coyne K. Outcomes from leiomyoma therapies: comparison with normal controls. Obstet Gynecol 2010;116(3):641-652

7 Spies JB. Sustained relief of leiomyoma symptoms by using focused ultrasound surgery. Obstet Gynecol 2007;110(6):1427-1428 , author reply $1428-1429$

8 Flake GP, Andersen J, Dixon D. Etiology and pathogenesis of uterine leiomyomas: a review. Environ Health Perspect 2003; 111(8):1037-1054

9 Ligon AH, Morton CC. Genetics of uterine leiomyomata. Genes Chromosomes Cancer 2000;28(3):235-245

10 Thiel RdoR, Dambros M, Palma PCR, Thiel M, Riccetto CLZ, Ramos MdeF. [Translation into Portuguese, cross-national adaptation and validation of the Female Sexual Function Index]. Rev Bras Ginecol Obstet 2008;30(10):504-510

11 Spies JB, Coyne K, Guaou Guaou N, Boyle D, Skyrnarz-Murphy K, Gonzalves SM. The UFS-QOL, a new disease-specific symptom and health-related quality of life questionnaire for leiomyomata. Obstet Gynecol 2002;99(2):290-300

12 Harding G, Coyne KS, Thompson CL, Spies JB. The responsiveness of the uterine fibroid symptom and health-related quality of life questionnaire (UFS-QOL). Health Qual Life Outcomes 2008;6:99

13 Boclin KdeL, Faerstein E, Szklo M. Does life-course socioeconomic position influence racial inequalities in the occurrence of uterine leiomyoma? Evidence from the Pró-Saúde Study. Cad Saude Publica 2014;30(2):305-317 